DEPARTAMENTO DE PSICOLOGIA

Curso de Especialização em Psicologia e Saúde

PACIENTE, FAMÍLIA E EQUIPE:

ASPECTOS PSICOLÓGICOS NOS CUIDADOS PALIATIVOS

Mariana de Almeida Ferreira

Mayla Cosmo

Orientadora

Rio de Janeiro, 29 de abril de 2011. 
DEPARTAMENTO DE PSICOLOGIA

Curso de Especialização em Psicologia e Saúde

Mariana de Almeida Ferreira

\section{PACIENTE, FAMÍLIA E EQUIPE: ASPECTOS PSICOLÓGICOS NOS CUIDADOS PALIATIVOS} Monografia apresentada ao
Programa de Pós-Graduação em
Psicologia da PUC-Rio como
requisito parcial para obtenção do
título de Especialista em Psicologia e
Saúde. Aprovada pela Comissão
Examinadora abaixo assinada.

Mayla Cosmo

Orientadora

Mônica Campioli

Rio de Janeiro, 29 de abril de 2011.

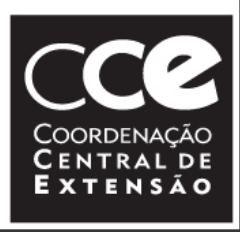


Dedico este trabalho a todos os pacientes que acompanhei em seus momentos finais de vida e que compartilharam comigo seus sentimentos e angústias 


\section{Agradecimentos}

À minha orientadora, Mayla Cosmo, além de grande participação no meu desenvolvimento pessoal e profissional, agradeço pelo incentivo em todos os meus projetos e, em especial, pelo carinho e cuidado ao orientar esse trabalho.

À minha família. Seu apoio e amor incondicional são a base para a minha produção.

À Juliana Mayerhoffer, por compartilhar o dia-a-dia da elaboração e produção desse estudo. Sempre disposta a discutir incansavelmente cada detalhe. Também por dividir e compartilhar vitórias e obstáculos da minha vida pessoal e profissional.

À Luana Souza, por sua doçura e disponibilidade para atender a todos os meu pedidos de socorro, além de ter se tornado, ao longo desse tempo, uma grande amiga e parceira profissional. 


\section{Resumo}

Um dos grandes medos da humanidade é o do sofrimento na hora da morte. Há a crença de que esse momento sempre é acompanhado de dor extrema e de um sofrimento insuportável e, até mesmo, de que há a necessidade do enfermo estar inconsciente nessa hora. Porém existem modelos alternativos de gestão de fim de vida, como os Cuidados Paliativos que destinam-se a assistir os pacientes sem possibilidade de cura, sendo um modelo de cuidado que considera o processo de morrer como parte da vida. O objetivo deste estudo é abordar os aspectos psicológicos do paciente, da família e dos profissionais de saúde envolvidos na prática dos cuidados paliativos. Utilizou-se a revisão bibliográfica como método investigativo. Realizou-se pesquisa nas bases de dados em língua portuguesa: SciELO, LILACS, BVS Psicologia, Index Psi Revistas TécnicoCientíficas, Index Psi Divulgação Científica, Index Psi TESES, Index Psi TCCs, PePSIC, Portal Revistas USP e Anais de Congressos em Psicologia. Também foram analisados livros e artigos que se encontravam nas referências bibliográficas das fontes indexadas. Recorreu-se às palavras-chaves terminalidade; cuidados de fim de vida; cuidados paliativos; aspectos psicológicos; abordagem psicológica. Conclui-se que o paciente, a família e equipe de saúde vivenciam situações e sentimentos que abalam e desorganizam seu psiquismo ao se depararem com a inevitabilidade da morte. Cuidar do psicológico desses sujeitos é tão necessário quanto cuidar do aspecto físico, do social e espiritual, pois são formados por todos eles e precisam ser compreendidos em todas as suas dimensões. Dessa forma, a presença do psicólogo dentro da equipe multiprofissional se faz fundamental, para auxiliar na elaboração dos sentimentos e questões suscitadas pelo processo do morrer.

Palavras-Chave: Cuidados Paliativos, Terminalidade, Aspectos Psicológicos, Cuidados de dim de vida, Abordagem Psicológica 


\section{Sumário}

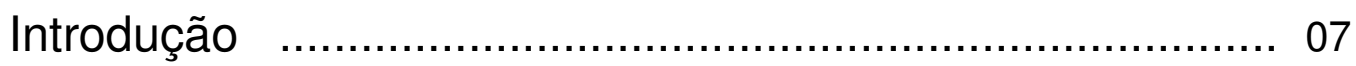

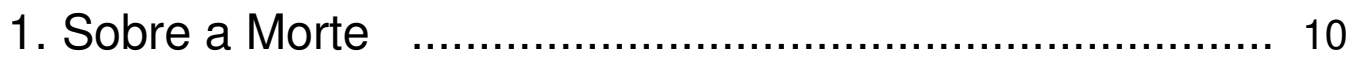

2. Cuidados Paliativos: Histórico e Conceitos ................... 14

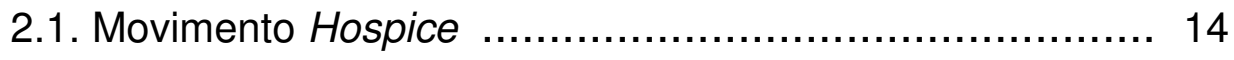

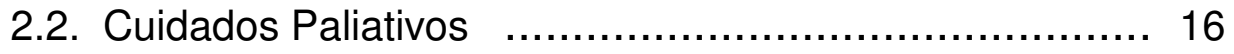

2.2.1. Cuidados Paliativos no Brasil ........................ 18

3. Aspectos Psicológicos em cuidados Paliativos ……..... 20

3.1. O Paciente ….................................................... 20

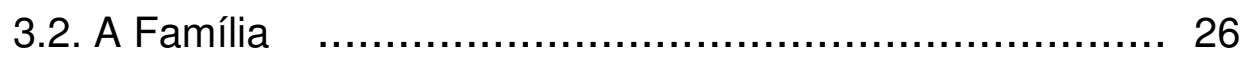

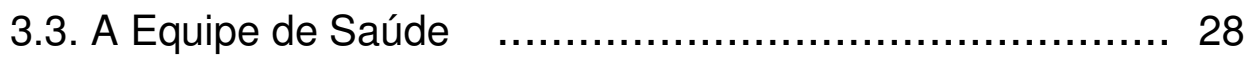

4. Bioética e Cuidados Paliativos ….............................. 32

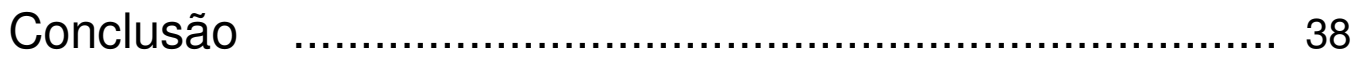

Referências Bibliográficas ............................................ 41 
"Eu me importo pelo fato de você ser você, me importo até o último momento de sua vida e faremos tudo o que está ao nosso alcance, não somente para ajudar você a morrer em paz, mas também para você viver até o dia da sua morte" Cecily Saunders 


\section{Introdução}

Um dos grandes medos da humanidade é o do sofrimento na hora va morte. Há a crença de que esse momento sempre é acompanhado de dor extrema e de um sofrimento insuportável e, até mesmo, de que há a necessidade do enfermo estar inconsciente nessa hora. Essas crenças são reforçadas por algumas práticas da medicina que, por vezes, utiliza medidas inúteis e dolorosas de sobrevivência, prolongando o sofrimento do paciente. Os hospitais gerais não estão equipados para oferecer a assistência que visa 0 cuidado, o alívio e o conforto (Kovács, 1992).

A partir da minha experiência como psicóloga hospitalar vivenciando a rotina dos pacientes em fase final de vida internados no Centro de Terapia Intensiva de um hospital privado de grande porte do Rio de Janeiro, surgiu o interesse em investigar os Cuidados Paliativos como uma abordagem alternativa para esses pacientes e, mais especificamente, os aspectos psicológicos do paciente, da família e da equipe de saúde diante da iminência de morte. "Como é realizada esta abordagem?". "Como se comportam paciente, família e equipe diante de uma doença incurável e em fase terminal?". "Que aspectos psicológicos surgem na prática dos Cuidados Paliativos?". "Que questões éticas permeiam essa abordagem?". Essas foram perguntas que emergiram ao pensar o tema.

Os cuidados paliativos destinam-se a assistir os pacientes sem possibilidade de cura, sendo um modelo de cuidado que considera o processo de morrer como parte da vida. Fundamenta-se em terapêuticas capazes de oferecer a esse paciente um cuidado focado no aumento da qualidade de vida, na diminuição dos sintomas e no respeito aos direitos individuais, utilizando a racionalidade terapêutica e a bioética como ferramentas. A família é vista como continuação do paciente e por isso também é assistida em todas as suas necessidades (Oliveira e Silva, 2010).

Segundo essa abordagem, o foco da atenção deixa de ser a doença a ser curada e passa a ser o indivíduo que é entendido como um ser biográfico, 
complexo em suas dimensões físicas, psíquicas e espirituais, ativo e com direito a informação e a autonomia para tomar decisões a respeito de seu tratamento, além da atenção personalizada a sua família e a busca da excelência no controle dos sintomas (Oliveira, 2008 apud Oliveira e Silva, 2010).

Porém questões relacionadas ao fim da vida e a limitação de tratamentos de suporte em pacientes com doenças em fase terminal ainda são considerados como tabu no Brasil e a discussão aprofundada sobre o tema foi negligenciada durante anos até bem pouco tempo (Soares, Terzi e Piva, 2007).

É dentro deste cenário que este trabalho se desenvolve e se propõe a compreender de forma integral os Cuidados Paliativos. A questão central do estudo diz respeito à dimensão psicológica envolvida desde o momento do diagnóstico de uma doença potencialmente fatal até o processo de morte do paciente.

Portanto, o objetivo deste estudo é abordar os aspectos psicológicos do paciente, da família e dos profissionais de saúde envolvidos na prática dos cuidados paliativos.

No Capítulo 1 ("Sobre a Morte"), serão retratadas as várias representações da morte ao longo da História a partir das referências de Phillipe Áries; os conceitos de "Morte Moderna" e "Morte Contemporânea", além da relação dessas representações com o desenvolvimento da prática da Medicina.

O aprofundamento histórico e conceitual do Movimento Hospice e dos Cuidados Paliativos é tema do Capítulo 2 ("Cuidados paliativos: Histórico e Conceitos"). Aqui serão abordados: a origem dos hospices, a criação dos primeiros hospices modernos, a importância do trabalho de Cecily Saunders e a contribuição fundamental de Elizabeth Kubler-Ross para os cuidados de fim de vida, a filosofia e a prática dos Cuidados Paliativos.

No Capítulo 3 (“Aspectos Psicológicos nos Cuidados Paliativos”), temática central deste estudo, poderemos conhecer mais de perto quem são os personagens desse cenário: "O Paciente", "A Família" e "A Equipe de Saúde". E os aspectos psicológicos que perpassam por eles ao vivenciarem os Cuidados Paliativos serão discutidos. 
O Capítulo 4 ("Bioética e Cuidados paliativos") centra-se nos princípios da bioética e nos assuntos polêmicos do fim de vida: Eutanásia, Distanásia, Ortotanásia, além da relação desta última com os Cuidados Paliativos.

Para atingir o objetivo deste estudo, utilizar-se-á revisão bibliográfica como método investigativo. Realizou-se pesquisa nas bases de dados em língua portuguesa: SciELO, LILACS, BVS Psicologia, Index Psi Revistas TécnicoCientíficas, Index Psi Divulgação Científica, Index Psi TESES, Index Psi TCCs, PePSIC, Portal Revistas USP e Anais de Congressos em Psicologia. Também foram analisados livros e artigos que se encontravam nas referências bibliográficas das fontes indexadas. Recorreu-se às palavras-chaves terminalidade; cuidados de fim de vida; cuidados paliativos; aspectos psicológicos; abordagem psicológica.

A investigação da abordagem dos Cuidados Paliativos e das questões psicológicas envolvidas nela se faz necessária para a aproximação da sociedade com esse modelo alternativo de gestão de fim de vida num momento onde todos os esforços estão sendo feitos para a rehumanização da saúde. 


\section{Sobre a Morte}

O morrer não é somente um acontecimento biológico, físico, mas um processo construído pela sociedade. Uma comunidade pode decretar a morte social de um indivíduo caso ele descumpra certas regras vigentes na mesma. Os sentidos dados ao processo de morrer e à doença são influenciados pelo momento da história e pelo contexto cultural e social (Menezes, 2004).

A morte e suas representações sociais e culturais têm sido objeto de estudo desde o início do século XX. Porém, somente após a Segunda Guerra Mundial é que o tema surge como foco de atenção de pesquisadores (Kóvacs, 1992).

Phillipe Áries, importante estudioso do tema, realizou vasta pesquisa sobre as mudanças nas representações da morte desde a Idade Média até o século XX. Cada período é caracterizado por uma forma de morrer: a "morte domada", a "morte de si mesmo", a "morte do outro" e a "morte invertida" (op. cit.).

A "Morte domada"

Característica da Idade Medieval. É a morte aceita pelo homem. A pessoa sabia que seu destino era morrer na guerra ou por epidemias e pragas. Era uma morte ritualizada, resignada e pública. A morte era aguardada pelo enfermo em seu leito, em sua casa, cercado de parentes, amigos e crianças que realizavam os rituais característicos daquela comunidade. A morte súbita era temida, pois não permitiria a realização dos rituais de despedida (op. cit.).

A "Morte de si mesmo"

A partir dos séculos XI e XII até o século XIV, o homem começa a questionar-se sobre o que acontecia após a sua morte, dando-se conta do limite de sua própria existência, de sua finitude. Surge o medo do juízo final, do julgamento da alma, do inferno. $O$ apego às coisas terrenas e materiais é 
condenado pela Igreja, surgindo, nesse momento, as orações e missas para os mortos, os ritos fúnebres e os testamentos (op. cit.).

\section{A "Morte do Outro"}

Considerada a morte romântica, é a morte do século XIX até o século $X X$. Aqui a morte é desejada, pois é vista como oportunidade de "reencontrar" os entes queridos, a possibilidade de repouso eterno. Por outro lado, a morte tornase insuportável pela separação que causa. O medo das almas penadas dá início aos rituais para afastamento desses "seres" e há receio das epidemias causadas pelos restos mortais. Começa a separação e o distanciamento entre mortos e vivos (Kóvacs, 1992).

\section{A Morte "Invertida"}

É a morte suja, vergonhosa, que se tenta esconder. A morte deveria passar despercebida. Passa a ser considerada um fracasso e, por isso, deveria ser silenciada. A morte é levada para os hospitais. Os cuidados com os doentes viram monopólio das instituições médicas e não mais são realizados pelas famílias em seus lares. A instituição hospitalar é bem-vinda nesse momento, pois camufla a morte e os aspectos repugnantes da doença: as secreções, os cheiros, os ruídos, o sofrimento (op. cit.; Menezes, 2004).

Até o século XVIII, a instituição hospitalar era comandada por religiosos, e realizava, basicamente, assistência às pessoas pobres e doentes. Não havia ainda a influência da medicina, apenas trabalho voluntário realizado por religiosos e por pessoas que almejavam a sua própria salvação através da caridade. O hospital excluía e segregava aqueles que perturbavam a ordem pública: pobres à beira da morte. Era um morredouro e não um lugar de cura (op. cit.).

O surgimento da disciplina e da ordem no espaço hospitalar propiciou sua medicalização. A evolução tecnológica e, conseqüentemente, as modificações nas práticas diagnósticas e terapêuticas, a produção de novos medicamentos e aparelhagem transformam o hospital em um instrumento terapêutico no fim do século XVIII (op. cit.). A partir daí, o poder exercido pelo saber médico promove a medicalização social, que pode ser entendida como a interferência da medicina 
no cotidiano das pessoas, impondo novas condutas sociais (Corrêa, 2001 apud Menezes, 2003). O processo de medicalização do social tem início no século XIX com grande e profundo desenvolvimento durante o século XX. A partir de então, questões sobre vida e morte, saúde e doença viraram exclusividade da medicina: é o surgimento da "morte moderna" (Marinho e Arán, 2010)

\section{A "Morte Moderna"}

No modelo moderno a morte é institucionalizada, solitária. O paciente sofre um processo de despersonalização, é silenciado para não perturbar o bom funcionamento hospitalar, raramente é comunicado sobre seu diagnóstico, não tem acesso à verdade sobre o que se passa com ele, é tolhido em seu direito de escolha e, freqüentemente, desconhece suas opções terapêuticas. Está absolutamente submetido ao saber e ao poder médico (Menezes, 2003).

O desenvolvimento da tecnologia e a criação de equipamentos para a manutenção artificial da vida (respirador artificial, diálise, monitoramento, etc) possibilitaram o surgimento de unidades altamente específicas (como por exemplo, as unidades de terapia intensiva). O morrer passa a ser confinado nesses centros especializados e manejado de forma mecânica, asséptica e impessoal (Menezes 2003; Menezes, 2004).

\section{A "Morte Contemporânea"}

No decorrer dos anos 60 e 70 do século XX, as críticas ao poder das instituições médicas, à prática de uma assistência racional e medicalizada, à perda de autonomia dos pacientes decorrente da submissão ao poder médico, promoveram a emergência de um discurso que propunha mudanças na forma de pensar o processo de morrer e suas práticas. A esse novo discurso foi dado o nome de "morte contemporânea" ou pós-moderna (op. cit).

Enquanto na visão da "morte moderna" a morte é considerada um fracasso pela equipe médica, no modelo contemporâneo, chamado de "boa morte", os médicos compreendem o morrer como um processo natural do desenvolvimento humano. $\mathrm{Na}$ "morte contemporânea" a proposta é que o indivíduo que está morrendo possa ter autonomia e controle sobre seu processo 
de morte. Seria a morte "escolhida" pelo próprio paciente em fase final de vida (Menezes, 2003).

O modelo de morte contemporânea traria à tona a discussão sobre os direitos do doente $\mathrm{e}$ as práticas médicas dando origem a movimentos alternativos de gestão de fim de vida: entre eles o Movimento Hospice e, posteriormente, os Cuidados Paliativos (Marinho e Arán, 2010). 


\section{Cuidados Paliativos: Histórico e Conceitos}

\subsection{Movimento Hospice}

$\mathrm{Na}$ Europa medieval, a partir do século IV, há relatos de estabelecimentos mantidos por religiosos que acolhiam viajantes em peregrinação para que pudessem se restabelecer fisicamente e retomar suas "jornadas". A tais estabelecimentos era dado o nome de hospice (Saunders, 2005 apud Floriani e Schamm, 2010).

A palavra hospice é originária do latim hospes, que significa estranho e posteriormente, anfitrião. A palavra hospitalis significa amigável, dando origem à palavra hospitalidade, ou seja, boas vindas ao estranho (Melo e Figueiredo, 2006).

Os hospices medievais tinham a função de abrigar, receber e ajudar os peregrinos a seguirem suas viagens, não eram locais destinados aos cuidados com enfermos e moribundos (Goldin, 1997 apud Floriani e Schamm, 2010).

O hospices modernos herdaram, de suas origens medievais, o termo hospice, o caráter acolhedor e a idéia de doença como uma "jornada a ser percorrida" pelo paciente e seus familiares. Porém, a especificidade que caracteriza os hospices modernos é que apenas aqueles indivíduos que estavam morrendo poderiam ser levados para lá. Eram locais que abrigavam e cuidavam, dentro da filosofia cristã, de pobres gravemente doentes que estavam morrendo e que os hospitais se recusavam a oferecer boa assistência (Goldin,1981 apud Floriani e Schamm, 2010).

Os primeiros hospices modernos têm data na Europa do século XIX, mais especificamente, na Inglaterra vitoriana. Tais hospices possuíam algumas características em comum como: a forte ênfase religiosa que orientava os cuidados espirituais prestados aos moribundos; eram instituições voltadas para as pessoas pobres; os cuidados físicos eram dados por enfermeiras, havendo pouco contato com os médicos; grande atividade de voluntários ligados à 
filantropia cristã; e pouca comunicação entre essas instituições (Goldin, 1981; Humphreys, 2001; Wislow, Clark, 2006 apud Floriani e Schamm, 2010).

Os hospices modernos surgiram como opção em um período onde a medicina passava por grande produção científica e os hospitais se estabeleciam como grandes centros de cura, voltados apenas para a vida, não havendo lugar para se morrer. Outro motivador para o surgimento dos hospices foi a necessidade das instituições cristãs da época reconquistarem seus membros, num momento onde sociedade inglesa estava se secularizando. (Humphreys, 2001 apud Floriani e Schamm, 2010)

São essas instituições do final do século XIX que deram origem, quase um século depois, ao Movimento Hospice, que tem em Cicely Saunders uma de suas mais importantes representantes.

Em 1967, a assistente social, enfermeira e médica Cicely Saunders funda o St Christopher's Hospice em Londres, que viria a ser um pólo de referência para o acompanhamento de pacientes em fase final de vida. É reconhecido como primeiro hospice moderno, pioneiro nos cuidados de fim de vida, tornandose um centro de excelência em pesquisa e ensino na área (Marinho e Arán, 2010).

Saunders já havia trabalhado em duas outras instituições, em uma como médica e em outra, inicialmente, como estudante de medicina e, posteriormente, como médica. Foi nesse período que iniciou seus estudos sobre o controle da dor de pacientes com câncer (Du Bolay, Rankin, 2007 apud Floriani e Schamm, 2010). A partir desses estudos, formulou o conceito de dor total, que seria todas as dores do paciente: dor física, emocional, social e espiritual, para representar o complexo sofrimento a que está exposto um paciente em fase final de vida (Clark, 1999 apud Marinho e Arán, 2010).

Somente a partir da fundação do St. Christopher's Hospice e da iniciativa de Saunders se tornar médica é que ocorre uma maior aproximação com o campo da medicina, tornando possível um aprofundamento nas pesquisas científicas e do ensino em cuidados paliativos, o que diferenciou o Movimento das atividades realizadas nos hospices da época (Humphreys, 2001 apud Floriani e Schamm, 2010). 


\subsection{Cuidados Paliativos}

O Movimento Hospice dá origem aos conceitos de Cuidados Paliativos. O termo paliativo deriva do vocábulo latino pallium que significa "coberta", "manta"; dessa forma, quando os sintomas não podem ser curados, eles são "cobertos" com procedimentos alternativos como, por exemplo, o alívio da dor. Em inglês palliare pode ser traduzido como proteger, suavizar, aliviar. Paliar pode ser entendido como: encobrir, disfarçar, dissimular, tornar aparentemente menos desagradável, remediar provisoriamente, aliviar (Pessini, 2006).

O termo Cuidados Paliativos possui um enfoque holístico que leva em consideração os aspectos físicos, psicológicos, sociais e espirituais do indivíduo (Pessini, 2006). São baseados em uma abordagem multidisciplinar e preocupam-se com os cuidados com o paciente, familiares e comunidade, oferecendo um cuidado total. $O$ foco principal é o cuidar e não mais o curar (Melo e Figueiredo, 2006).

Em 1990, a Organização Mundial de Saúde (OMS) conceituou Cuidados Paliativos como cuidados ativos e totais que promovem qualidade de vida aos pacientes e seus familiares diante de doenças sem possibilidades curativas, por meio de alívio e prevenção de sintomas, sendo necessário avaliação e tratamento da dor e de outros sintomas físicos, psicológicos, sociais e espirituais (World Health Organization - WHO, 2002).

A filosofia dos cuidados paliativos está baseada em: promover a vida e ver a morte como um processo natural do desenvolvimento humano; não antecipar e nem prolongar a morte; oferecer auxílio para que o paciente possa viver o mais ativamente possível até o momento de sua morte; ajudar os familiares a enfrentar o processo de luto (Pessini, 2006).

Segundo essa proposta, o ideal é que o paciente tenha controle de seu processo de morte, podendo fazer suas escolhas. A comunicação entre o paciente, familiares e equipe médica deve ser a mais franca possível, propiciando a discussão sobre tempo restante de vida, técnicas e procedimentos 
a serem usados ou não e sobre os desejos do paciente e dos familiares. (Menezes, 2004)

A assistência paliativa pode ser definida como uma garantia de "qualidade de vida" para o período final da vida daqueles que não podem mais ser curados, sendo uma abordagem diferente da prática médica exercida até o momento: manter a vida a qualquer preço. Para os Cuidados Paliativos a qualidade de vida é mais importante do que a quantidade de vida às custas de dor e sofrimento (Menezes, 2004).

Uma teoria específica sobre a assistência aos pacientes em fase final de vida foi elaborada a partir do conceito de dor total de Cecily Saunders, de pesquisas farmacológicas e da teoria das cinco fases de Elizabeth Kubler-Ross.

A teoria de Kubler-Ross passou a ser referência para a escuta dos pacientes terminais e para a compreensão de seus sentimentos em relação à aproximação da morte. As etapas: negação, raiva, barganha, depressão e aceitação podem ser vivenciadas pelo paciente e/ou por seus familiares. Tal teoria proporcionou uma mudança na representação do morrer, pois, a partir desse momento, a fase final da vida ganhou um lugar oficial, passou a ser vista $e$ reconhecida em toda sua complexidade (op. cit.).

Nesse contexto, o paciente passa o ocupar o papel central do processo do morrer, a ser o ator principal de sua morte, ganhando voz e demandas particulares e abre-se um novo espaço de intervenção para profissionais dedicados ao controle de dor, ao trabalho social e ao atendimento psicológico (op. cit.).

Tratar paliativamente não quer dizer abandonar os recursos terapêuticos, mas utilizá-los de forma racional e diretamente voltada para focos bem definidos: o controle de sintomas que provocam a perda da qualidade de vida, a garantia da dignidade, a promoção do bem-estar e o apoio emocional e espiritual aos doentes. Nos cuidados paliativos, tenta-se evitar a realização de exames desnecessários, conhecidos como exames "para documentação" ou com a única finalidade de checar parâmetros bioquímicos e morfológicos, assim como utilizar recursos tecnológicos apenas porque estão disponíveis ou por medo da "omissão de socorro". A mudança do cuidado ativo para o cuidado paliativo é um 
processo e cada paciente passará por essa transição de sua maneira, de acordo com a sua dinâmica (Caponero e Vieira, 2006).

Os cuidados paliativos se apresentam sob várias formas: clínica-dia, internação, assistência domiciliar e suporte para o luto e podem estar inseridos em casas de repouso, moradias assistidas, hospices e na própria instituição hospitalar (Melo e Figueiredo, 2006):

- Clínica-dia: na fase crônica da doença, o paciente recebe cuidados diários e é orientado por uma equipe de saúde multidisciplinar. Quando tem condições, é encaminhado para sua casa.

- Assistência Domiciliar: utiliza serviços e equipamentos especializados que dão ao paciente um atendimento integral em seu próprio lar, propiciando uma ambiente familiar.

- Internação hospitalar: cuidados paliativos prestados dentro de uma instituição hospitalar.

Quando estão inseridos no hospital, percebe-se que são iniciativas isoladas e esforços individuais de alguns profissionais que "levantam a bandeira" da importância dos cuidados paliativos dentro da unidade hospitalar. Em todas as modalidades de serviços, o paciente deve receber cuidados contínuos e ser assistido de perto pela equipe de saúde (Silva e Hortale, 2006).

\subsubsection{Cuidados paliativos no Brasil}

A trajetória dos cuidados paliativos no Brasil seguiu o mesmo caminho de outras partes do mundo. Até 1950, a medicina era feita de forma familiar e, apenas em 1980, o conceito de cuidado total com paciente começou a ser mais difundido. No Brasil, o desenvolvimento dos cuidados paliativos também pode ser considerado como esforço e empenho de poucos profissionais indignados, especialmente na oncologia e geriatria do Rio de Janeiro e São Paulo. Em 1998, o Ministério da Saúde inaugurou no Instituto Nacional do Câncer - INCA (Rio de Janeiro), o Centro de Suporte Terapêutico Oncológico - CSTO - que seria a primeira Unidade Hospitalar de Cuidados Paliativos. Esse tipo de assistência já vinha se desenvolvendo no INCA desde 1986, porém apenas muito tempo depois foi elaborada uma proposta de assistência domiciliar para os pacientes considerados "fora de possibilidades terapêuticas" com a finalidade de liberar 
leitos para tratamento especializado em câncer no hospital. Foram necessários 10 anos para que a filosofia dos cuidados paliativos nos moldes dos hospices ingleses se consolidasse no INCA. Na década de 1990, outros serviços hospices surgiram em São Paulo, no sul e no interior do Brasil. Assim como na maioria dos outros países, aqui os cuidados paliativos são desenvolvidos em instituições de assistência e ensino e são tema em diversos eventos científicos da área da saúde atualmente. Porém, muito ainda se tem a fazer pelo futuro dos cuidados paliativos no Brasil, necessitando de incentivos ao ensino e mais investimento em pesquisas. O trabalho desenvolvido, hoje, no Brasil se utiliza de índices estrangeiros os quais nem sempre correspondem à nossa realidade social. Para garantir o desenvolvimento dos cuidados paliativos no país é preciso que os nossos profissionais atuantes na área se engajem cada vez mais na comunidade científica e na produção e disseminação de conhecimento desse tipo de assistência (Teixeira e Lavor, 2006). 


\section{Aspectos Psicológicos em Cuidados Paliativos}

\subsection{O Paciente}

A adaptação do paciente aos cuidados paliativos depende de vários fatores: natureza da doença, idade do paciente, momento do desenvolvimento familiar, do padrão de enfrentamento do paciente e da família em situações de crise, das experiências prévias em relação à doença e à perda, da classe social e econômica e de variações culturais envolvidas no processo de fim de vida (Melo e Figueiredo, 2006).

Weisman (1972, apud Kovács 1992) estabelece três estágios para a doença terminal:

- Estágio 1: Dos primeiros sintomas até receber o diagnóstico. Nesse estágio, os mecanismos de defesa mais observados são a negação e o deslocamento.

- Estágio 2: Do diagnóstico até a fase terminal. É o estágio em que a maior parte do tratamento está concentrada, cujo objetivo principal é curar a doença. Nesse estágio, há uma alternância entre os mecanismos de negação, abrandamento e deslocamento até alcançar a aceitação da irreversibilidade do quadro clínico.

- Estágio 3: Momento em que o tratamento ativo diminui e investe-se mais na busca de alívio de sintomas e cuidados pessoais.

Cada estágio favorece uma percepção específica de vida e morte, sendo as necessidades do paciente muito diferentes em cada período.

O apoio psicossocial no momento terminal da doença é fundamental, uma vez que, segundo os valores da sociedade contemporânea, a morte é tratada com preconceitos e estigmas que envolvem uma série de elementos que amedrontam o homem. Segundo Morais (2000, apud Oliveira, Santos e Mastropietro,2010), esses elementos seriam: 
1) O conhecimento da própria finitude;

2) A solidão: a morte seria o momento da solidão absoluta;

3) $O$ fim da rede existencial, a extinção dos relacionamentos pessoais;

4) O temor pelo sofrimento do processo de morrer;

5) A hipótese do nada: o receio de não haver nada depois da vida (Morais, 2000 apud Oliveira, Santos e Mastropietro,2010).

Para Oliveira, Santos e Mastropietro (2010), talvez por se deparar com aspectos tão apavorantes, o homem se recuse a pensar que sua finitude é inevitável. Essa recusa é ameaçada no momento em que recebe o diagnóstico de uma doença potencialmente fatal e se confronta com o destino da terminalidade. Pierre (1998 apud Oliveira, Santos e Mastropietro, 2010) aponta que, diante desse primeiro contato com a enfermidade, surgiriam características típicas como o choque, o inconformismo, peregrinação em busca de diversas opiniões médicas especializadas. O paciente pode passar ainda por momentos de agressividade direcionada ao meio, à família, à equipe de saúde e a Deus. O sentimento de impotência é predominante frente à perda da própria integridade física.

No momento em que uma pessoa adoece, ela pode não ser capaz de realizar e satisfazer suas necessidades físicas, psicológicas, sociais e espirituais da mesma forma como fazia até então. Novas demandas, inseguranças e incertezas podem aparecer. (Fitch, 2006)

Ao se deparar com a possibilidade e proximidade da própria morte, inúmeras emoções emergem e cada pessoa reagirá de uma maneira. Uma gama de preocupações surgem à medida que o paciente começa a imaginar o fim da própria vida, o que vai acontecer com ele e com quem ele ama. Preocupações legais, financeiras, com a sua própria dependência, com tarefas inacabadas, com a sobrecarga da família. Algumas vezes, o paciente sente-se muito sozinho, imaginando que ninguém pode compreender seus receios e seus sentimentos (op. cit.).

A doença faz remeter a pensamentos de vulnerabilidade e perda de controle da própria vida. O paciente começa a perceber que seu corpo não funciona mais como antes e que não consegue fazer mais tudo o que deseja. Além da imagem 
corporal, a percepção de si mesmo e sua autonomia também sofrem mudanças. A angústia psicológica surge quando as expectativas, metas e relacionamentos importantes não conseguem mais ser mantidos pela pessoa. Tal angústia pode se apresentar como ansiedade ou depressão vivenciadas em diferentes níveis de intensidade. É esperado que as pessoas que estão vivenciando um processo de morte apresentem ansiedade e por isso, ter alguém para conversar e confiar faz bem para todos, porém aqueles pacientes que apresentarem níveis moderados e severos de ansiedade podem ser beneficiados com a ajuda de um profissional da saúde mental. Os pacientes com maiores riscos de apresentar depressão são aqueles com doença avançada, grandes restrições físicas, dor elevada, comorbidades, histórico de transtornos psicológicos ou alcoolismo e suporte social escasso (Fitch, 2006).

Segundo Eisseler (1979, apud Kovács, 1992), o paciente em fase final de vida regride e necessita de cuidados maternais e conforto físico. Como se precisasse de um ego auxiliar, um ego externo, assim como as crianças necessitam de suas mães para sobreviverem. Como na primeira infância, sofre com a ansiedade de separação.

Para Lamerton (1980 apud Kovács, 1992), nos pacientes em fase terminal da doença é importante tratar os sintomas e não a doença e um dos sintomas mais destrutivos é a dor.

A dor é um fenômeno universal e, ao mesmo tempo, particular, com uma variedade de sentimentos, sensações e significados. É proveniente de algum dano sofrido pelo corpo ou pela mente (Carvalho e Merighi, 2006).

Os aspectos emocionais estão relacionados diretamente com a experiência da dor, podendo aumentá-la ou diminuí-la. O medo, por exemplo, aumenta a sensação de dor através de uma contração tanto física quanto psicológica. Outros aspectos como a sensação de falta de controle, de abandono, de isolamento também podem fazer a pessoa sentir mais dor. Uma dor muito intensa pode desorganizar o aparelho psíquico, afetando a capacidade de desejar e o ato de pensar (Anzieu, 1985 apud Kóvacs, 1999). Em contrapartida, dores insuportáveis podem ser toleradas e enfrentadas com coragem caso o indivíduo sinta-se apoiado (Kóvacs, 1999). 
A dor pode, também, ser entendida como um importante meio de comunicação. Assim como a dor física expressa que algo não está bem com o nosso corpo, a dor psicológica significa que algo não está bem no nosso psiquismo. É importante que prestemos atenção a esses sinais, qual o teor dessa comunicação, a quem está sendo dirigida, o que pode estar faltando para esse paciente e quais são suas carências. Essa dor pode ser um pedido de ajuda, de cuidado ou de consolo (Kóvacs, 1999).

Para Kovács (2005), o medo é a resposta psicológica mais freqüente diante da morte. Em pesquisa realizada com pacientes com doença em fase terminal, Parkes (1991, apud Kóvacs, 1999) aponta que o medo é um sentimento muito presente e que está diretamente relacionado com a incerteza do que irá acontecer. Alguns dos medos mais comuns são:

- Medo da dependência: medo de perder a autonomia e necessitar da ajuda de terceiros para a realização de atividades diárias;

- Medo do que acontecerá com seus familiares após sua morte: como irão se sustentar financeiramente e como irão se desenvolver pessoalmente;

- Medo de não conseguir realizar suas metas pessoais: medo de morrer antes de realizar o que tinha planejado, coisas que ainda gostaria de fazer, não ver o crescimento de filhos e netos, não estar presente em datas importantes;

- Medo da dor e da mutilação: medo de não suportar a dor, de não receber os cuidados adequados, da degeneração de seu corpo, das perdas físicas e psíquicas;

- Medo da morte: medo da finitude, de ser esquecido.

O paciente gravemente doente vivencia inúmeras perdas que podem ser consideradas como uma morte simbólica, morte de partes de si mesmo. O luto pode acontecer pela "perda de si" como pessoa ativa, profissional, cônjuge, genitor, perda da capacidade de gerenciar a própria vida; E pela "perda do outro", de seus entes queridos, de seus familiares e amigos (Kóvacs, 1999).

O paciente em fase final de vida precisa receber assistência contínua e necessita estar em contato com pessoas. A melhor maneira de demonstrar que o paciente está sendo bem cuidado é reserva-Ihe tempo. É importante estar atento para as mudanças de comportamento do paciente, como alterações da auto- 
estima e distanciamento de seus interesses rotineiros. Pode ser uma forma de comunicar que algo não vai bem. Encorajar o paciente a confiar na equipe, mostrar que ele é respeitado, que não será abandonado e rejeitado traz conforto e tranqüilidade (Muccillo, 2006).

É importante atender aos desejos dos pacientes como: visitar desesperadamente um lugar, necessidade de reatar laços com alguma pessoa, compreender sonhos e expressões não-verbais. É necessário, também, que a comunicação seja facilitada, através de um processo de escuta mútua com a possibilidade de verbalização do não-dito e de expressão de sentimentos. No processo psicoterapêutico o desejo pode ser trabalhado e, mesmo durante o período de grave adoecimento nós, psicólogos, podemos facilitar, através dos insights do paciente, o autoconhecimento, o aprofundamento de certas relações, a resignificação de eventos da vida e de valores, a elaboração de algumas questões e da própria situação de doença em que se encontra. Para a realização desse tipo de trabalho, faz-se necessário que o paciente tenha sua estrutura de ego preservada e que queira se submeter a esse processo. Porém, em alguns casos, o paciente pode estar muito fragilizado e ficar muito angustiado ao reavivar certas emoções, sendo indicada nesses casos, uma abordagem apenas de suporte e de apoio (Kóvacs, 1999).

Callanan e Kelly (1994, apud Oliveira, Santos e Mastropietro, 2010) afirmam que é freqüente observar em pacientes em fase terminal da doença falas "confusas" e metáforas repetitivas, como a metáfora sobre "a viagem", que seria o percurso do fim de vida. É importante que essas falas e metáforas não sejam desqualificadas, pois, segundo as autoras, os pacientes se utilizam, freqüentemente, de uma linguagem simbólica para expressar suas experiências e sensações diante da iminência da morte.

A compreensão empática é fundamental, para que possamos nos colocar no lugar do paciente e enxergar o mundo a partir dos olhos dele, adquirindo uma postura desprovida dos nossos valores e crenças (Oliveira, Santos e Mastropietro, 2010).

Os pacientes encaram a doença e seu tratamento de acordo com a sua personalidade, sua história de vida, suas crenças e seu contexto social e cultural. É importante compreender o quadro clínico e as particularidades de 
cada pessoa para ajudar o paciente a traçar suas estratégias de enfrentamento. Investigar fantasias, perdas, medos, favorecer a elaboração desses conteúdos, de expectativas e frustrações, explorar as formas de enfrentamento são meios de propiciar possibilidades para o ajustamento do paciente à nova situação (Prade, Caselato e da Silva, 2008).

Margareth Fitch (2006) afirma que duas metas principais devem servir de base para a atuação com pacientes em processo de morrer: 1) reduzir o impacto dos sintomas e efeitos indesejados e 2) auxiliar o paciente a enfrentar as situações. Para que essas metas sejam atingidas, é fundamental que as intervenções sejam direcionadas pelo próprio paciente. Uma conversa inicial buscando identificar desejos e sua real situação deve ser o ponto de partida. $O$ foco dessa primeira abordagem deve ser o envolvimento do paciente em tomar decisões sobre si mesmo e se está informado o suficiente para que participe no processo da maneira desejada. O indivíduo precisa ter abertura para expressar suas preocupações, dúvidas e perguntas e ter certeza que não será julgado ou criticado. A interação e abordagens ao paciente e família devem ser constantes, pois, com o passar do tempo, as situações mudam assim como as idéias e pensamentos das pessoas. Apenas com diálogos freqüentes a equipe estará garantindo um cuidado baseado nas necessidades do paciente.

Observar e potencializar os aspectos positivos da personalidade, como criatividade, senso de humor e espiritualidade são atitudes que beneficiam paciente e família. A elaboração de conteúdos através de atividades criativas é uma ferramenta interessante para o paciente utilizar na busca de significados e respostas. Atividades como poesia, música, pintura, dança, literatura, artesanato entre outras podem ser usadas como formas simbólicas de integração de experiências e elaboração de conteúdos (Prade, Caselato e da Silva, 2008).

Um vínculo paciente-equipe adequado contribui para uma boa comunicação e para a segurança do paciente, pois mudanças de opinião e de quadro clínico podem acontecer durante o tratamento (op. cit.).

O paciente, nos momentos finais de sua vida, tende a voltar-se mais para seu mundo interior e a ficar menos comunicativo. Tal atitude, muitas vezes, é confundida por profissionais e familiares como rejeição ou recusa à interação, o que nem sempre é real, pois o que pode estar acontecendo é um desligamento 
do paciente com o mundo exterior, deixando-o de lado, para mergulhar em sua interioridade. Por isso, é aconselhável que a família não espere para se comunicar com o paciente em seus momentos finais (Pessini, 2006).

\subsection{A Família}

Estar diante da possibilidade da morte do "outro" é enfrentar a possibilidade da nossa própria morte. É, de certa forma, abrir a "caixa de Pandora" e encarar tudo aquilo com o que não conseguimos lidar e enfrentar na vida: nossas perdas temidas ou não resolvidas, nossos planos frustrados, nossas questões inacabadas e também tudo aquilo que projetamos para um futuro indefinido e distante, como se a vida fosse infinita, como se nós fossemos imortais (Prade, Casellato e da Silva, 2008).

Quando uma pessoa adoece e tal adoecimento ameaça sua vida, muitas mudanças acontecem. Mudanças no campo físico, social, psicológico e espiritual não só do paciente, mas também da família. Todos sentirão o choque da doença e, conseqüentemente, uma perturbação emocional. Quando a ameaça da doença torna-se realidade e a morte se aproxima, as emoções são intensificadas (Fitch, 2006).

Ao saber do diagnóstico de uma doença grave, a família passa pelas mesmas fases do paciente e o enfrentamento da mesma vai depender da estrutura de cada família e da relação entre seus membros. Podem aparecer processos como luto antecipatório, ambivalência de sentimentos, medo de presenciar a decadência da pessoa amada e impotência de não poder aliviar seu sofrimento. O sentimento de culpa é muito freqüente assim como a tentativa de reparação (Kovács, 1992).

Segundo Kubler-Ross (1996), com a internação do paciente, a família também sofre uma desestruturação em sua rotina, precisando reorganizar funções e papéis dentro do contexto familiar.

Ao perceber que a morte se aproxima e é inevitável, a família vivencia sentimentos de perda e sintomas depressivos, como tentativa de adaptação física e psicológica às conseqüências da morte real. É o chamado luto antecipatório. É necessário perceber que a família pode estar passando por esse 
momento de perda antecipada. É importante compreender que cada membro dessa família pode reagir de uma forma para demonstrar seu pesar, e nós precisamos evitar o julgamento ou desaprovação dessas reações (Muccillo, 2006).

A tarefa de cuidar do paciente em casa é quase sempre exclusiva da família. Os cuidadores informais, como passam a ser chamados os membros da família que assumem os cuidados e os cuidadores profissionais contratados, necessitam de orientação e informação sobre a doença, de como exercer os cuidados e também de suporte psicológico e social (Silva e Hortale, 2006).

A ansiedade referente a medos irreais pode ser diminuída caso os cuidadores estejam bem informados sobre a doença do paciente, pois a maioria deles não tem formação em enfermagem e são beneficiados com instruções práticas de como cuidar do doente. Ansiedade, depressão, distúrbios do sono e perda de peso são sintomas prevalentes entre os cuidadores. Outros dois aspectos devem ser observados: as condições necessárias à realização dos cuidados na residência e as condições que, de fato, a família tem para ser responsabilizada pelos mesmos. Altos gastos com o paciente, baixo nível de renda, baixa escolaridade da família, carência de serviços públicos e saneamento básico precário são indicadores que podem dificultar o cuidado domiciliar (op. cit.).

Quando o processo de morte do paciente é muito longo, quando o final demora acontecer, a família precisa reinvestir na vida, cuidar de si, refletir e aceitar a morte, senão a família também "morre" ao cuidar do paciente (Kóvacs, 1992). A demanda que a família apresenta diante de uma situação de doença grave ainda é pouco atendida. A constatação de depressão, ansiedade e estresse e o encaminhamento para apoio psicológico/psiquiátrico aos familiares cuidadores propiciariam um melhor manejo da situação. A família também precisa ser cuidada. Os familiares, geralmente, reduzem suas necessidades, porém isso não significa que eles estejam bem e não necessitem de ajuda. As responsabilidades que a família assume diante de uma situação de doença são muitas e costumam produzir estresse e angústia. Oferecer um espaço onde os familiares possam expressar sentimentos, relembrar momentos de vida do paciente, reconhecer os novos papéis assumidos por cada um dentro da dinâmica familiar pode contribuir para uma melhor comunicação e adaptação da 
família à situação além de oferecer acolhimento. Indiretamente, o apoio aos familiares beneficia o paciente (Prade, Casellato e da Silva, 2008).

Oferecer ajuda prática para a família nesse momento também é de grande valia, pois, freqüentemente, ela está atordoada. Informar sobre a necessidade de registro do atestado de óbito em cartório, sobre o funeral, sobre documentos necessários, enfim, sobre questões burocráticas que geralmente a família desconhece ou não consegue pensar nesse momento, pode ajudar no momento de crise (Muccillo, 2006).

\subsection{A Equipe de Saúde}

Para atender às demandas e cuidados necessários dos pacientes em fase final de vida e seus familiares, entra em cena a equipe multiprofissional, os paliativistas, composta por médicos, enfermeiros, nutricionistas, psicólogos, fisioterapeutas, assistentes sociais e, também, por representantes religiosos (Menezes, 2004).

Uma equipe de cuidados paliativos precisa estar disponível para reconhecer sinais de emergência, amenizar o sofrimento físico e psíquico, dar segurança aos doentes, identificar problemas, tratar as queixas e reclamações de forma individual e poder responder às dúvidas tanto dos pacientes quanto da família e, principalmente, ouvir o paciente. Para tanto, o treinamento dessa equipe deve ser intenso, fazendo com que esses profissionais adquiram tais habilidades, propiciando uma assistência efetiva e bem sucedida (Melo e Figueiredo, 2006).

Segundo Fitch (2006), profissionais de saúde, principalmente os que trabalham com cuidados paliativos, devem ter em mente que duas pessoas nunca irão reagir da mesma maneira em uma situação igual, pois respondem de acordo com sua própria percepção e interpretação daquela situação, levando a um enfrentamento emocional e comportamental diferentes. O profissional não deve julgar e precisa compreender a perspectiva do paciente e da família, levando em consideração que pode demorar um tempo para que uma relação de confiança se estabeleça a ponto da pessoa sentir-se confortável para conversar sobre sentimentos dolorosos e assuntos difíceis, como perdas e desafios a serem enfrentados. É importante que o profissional seja capaz de deixar de lado 
seu modo de pensar uma situação e suas opiniões pessoais para compreender as atitudes e pensamentos do paciente e da família na condução do caso, identificando valores, sonhos, desejos e metas que devem ser respeitados.

O que nos caracteriza como seres humanos é a nossa capacidade de falar sobre nós mesmos e a capacidade de ouvir, não só ouvir a nós mesmos, mas ouvir aos outros. Em cuidados paliativos, a comunicação dos profissionais com o doente e a família é imprescindível. A comunicação clara, efetiva e focada nas necessidades do paciente ajuda no controle do sofrimento físico, promove o acolhimento emocional, auxilia no alívio da angústia e ajuda o paciente e família a desenvolverem o processo de se desligarem uns dos outros. A boa comunicação em cuidados paliativos é um processo de amadurecimento e reflexão pessoal, onde é necessário aprender a escutar e a falar, a comunicar notícias ruins, a autocuidar-se e ser cuidado, a reconhecer e aprender a lidar com a angústia que a doença em fase terminal traz (Kovács, 2006).

A comunicação entre a própria equipe de saúde é fundamental e deve ser coerente, pois pacientes e familiares costumam verificar várias vezes uma mesma informação recebida. Informações coerentes e de acordo com as passadas pelo restante da equipe dão credibilidade e fortalecem o vínculo de confiança (Melo e Figueiredo, 2006). Quando a equipe apresenta disponibilidade para informar adequadamente pacientes e familiares, observa-se a diminuição da ansiedade e aumento da adesão ao tratamento (Carvalho, 2006).

A discussão dos casos clínicos entre os profissionais da equipe é extremamente importante, pois enriquece o histórico do paciente e da família e contribui para a troca entre as especialidades, promovendo o crescimento profissional e o trabalho multidisciplinar (Melo e Figueiredo, 2006).

A experiência de observar a morte de uma pessoa de perto, na maioria das vezes, é uma situação que desgasta e esgota emocionalmente o profissional comprometido que lida com pacientes em fase final de vida e suas famílias (Muccilo, 2006). Entre os profissionais de saúde, a morbidade psicológica é alta, pois estão sujeitos a diversos aspectos estressantes que podem ser externos e internos. A doença em si, a resposta do paciente à doença e ao tratamento, a fase do tratamento, a qualidade de relacionamento interpessoal da equipe e a oferta escassa de recursos humanos e materiais para o trabalho podem ser 
exemplos de estressores externos. Já os internos podem estar relacionados com as próprias características do profissional como rigidez, sentimento de onipotência e nível de satisfação com o trabalho desenvolvido (Carvalho, 2006).

$\mathrm{Na}$ tentativa de evitar a angústia, o profissional acaba se utilizando de mecanismos de defesa socialmente estruturados como a quebra da relação profissional / paciente, a despersonalização do paciente, o distanciamento de seus próprios sentimentos, a tentativa de diluir as decisões para reduzir o peso das responsabilidades (Carvalho, 2006).

Eventualmente, essa situação pode levar ao surgimento da Síndrome de Burn-Out ${ }^{1}$ (síndrome de estresse profissional), quadro que acomete profissionais engajados em seus trabalhos e que apresenta sintomas somáticos, comportamentais e psíquicos. Estudos mostram que o estresse apresentado por alguns profissionais de saúde é semelhante ao nível de estresse de pessoas que apresentam quadro de distúrbio pós-traumático em conseqüência de desastres (op. cit.).

Outro fator importante na geração de estresse a ser considerado está relacionado com a ética. A alta tecnologia disponível atualmente, questões referentes ao momento de supressão do tratamento, eutanásia e distanásia são alguns aspectos que podem sobrecarregar os profissionais. Nos serviços em que a equipe de saúde tem uma relação sólida, em que é ouvida, em que seus membros podem expressar seus pontos de vista, há menos estresse profissional. Assim como nos serviços que há mais afeto e nos quais os profissionais sentem-se cuidados, verifica-se aumento da produtividade (op. cit.).

Os profissionais de saúde que atuam com a vida e a morte diariamente precisam adquirir condições psicológicas para estar nesta função (Muccillo, 2006). Zelar pela saúde metal dos profissionais é fundamental não só para eles mesmos, mas também para se manter a qualidade dos cuidados oferecidos aos

\footnotetext{
${ }^{1}$ Burn-out Syndrome é quadro de estresse que aparece em profissionais comprometidos com seus trabalhos e que é composto por sintomas somáticos, psíquicos e comportamentais. Sintomas somáticos: exaustão, fadiga, cefaléias, distúrbios gastrointestinais, insônia e dispnéia. Sintomas psíquicos: humor depressivo, irritabilidade, ansiedade, rigidez, negativismo, ceticismo e desinteresse. Sintomas comportamentais: comportamentos de evitação, rótulos depreciativos atribuídos ao cliente, comportamento crítico e ataques às pessoas e instituições (Carvalho, 2006).
} 
pacientes. Oferecer treinamentos constantes, supervisão clínica adequada que inclua as múltiplas dimensões do cuidado (física, psicológica, social e espiritual), grupos de auto-ajuda, desenvolvimento do autoconhecimento, serviço de apoio psicológico para demandas de caráter pessoal e profissional são estratégias sugeridas para melhorar a saúde mental dos trabalhadores (Silva e Hortale, 2006).

A reflexão sobre a morte e morrer e a permissão de tempo e espaço para a reestruturação das emoções ainda não são preocupações em grande parte das instituições e que, raramente, oferecem apoio psicológico a seus profissionais (Colatusso, Santos, Andrade e Dyniewicz, 2006).

$\mathrm{Na}$ prática dos cuidados paliativos, o profissional de saúde vivencia a morte do outro, se espelhando e até mesmo se misturando com as histórias que presencia. Dessa maneira, além da possibilidade de desenvolver suas habilidades técnicas e profissionais, pode buscar seu autoconhecimento e a libertação do medo de enfrentar suas perdas e desafios (Prade, Casellato e da Silva, 2008). 


\section{Bioética e Cuidados Paliativos}

O termo "Bioética" surgiu em meados do século XX, a partir do progresso tecnológico da Biologia e dos problemas éticos provenientes das práticas e intervenções das ciências biológicas sobre a vida e a natureza. Com a epidemia da AIDS, a partir dos anos 80 , a Bioética ganhou destaque, promovendo reflexões "bioéticas" diante das conseqüências dessas práticas para os indivíduos e para a sociedade (Koerich, Machado e Costa, 2005).

Podemos conceituar como Bioética o estudo sistemático, multidisciplinar da conduta humana nas ciências da vida e da saúde, na medida em que esta conduta é examinada a partir dos valores e princípios morais (Fortes, 1994). O comportamento ético em saúde deve ter, também, um enfoque de responsabilidade social e de direitos da cidadania, uma vez que sem cidadania não há saúde (op. cit.).

Os cuidados paliativos trouxeram de volta, no século $X X$, a possibilidade de rehumanizar a morte. A morte volta a ser vista como uma parte do processo da vida e diante de uma situação de doença, os tratamentos devem priorizar a qualidade da vida e o bem-estar do sujeito, mesmo quando curar não é possível (Kovács, 2003).

A boa prática dos cuidados paliativos está baseada em princípios da bioética como respeito à beneficência, não-maleficência, autonomia e justiça (Caponero e Vieira, 2006):

- Beneficência: é o dever de ajudar aos outros, de promover o bem a favor de interesses do paciente. O valor moral do outro é reconhecido e leva-se em conta que, maximizando o bem do outro, provavelmente pode-se diminuir o mal feito a ele. O profissional compromete-se a buscar o máximo de benefícios e a reduzir ao mínimo os danos e riscos. Para fazer uso deste princípio é preciso o desenvolvimento de competências profissionais, pois apenas desta maneira, é possível decidir quais são os riscos e benefícios aos quais os pacientes serão expostos diante de determinadas atitudes, práticas e procedimentos (Koerich, Machado e Costa, 2005). 
- Não-maleficência: o profissional tem o dever de não fazer qualquer mal para o paciente, de não causar danos ou colocá-lo em risco. É preciso avaliar e evitar os danos previsíveis. Segundo este princípio, é necessário evitar qualquer situação ou técnica que exponha o paciente a riscos, verificar se o modo de atuação não está prejudicando-o individual ou coletivamente e se existem outras práticas menos arriscadas, não bastando apenas, que o profissional tenha boas intenções de não prejudicar o paciente (Koerich, Machado e Costa, 2005).

- Autonomia: conceito fundamental da bioética, a autonomia apresenta duas condições essenciais: liberdade (independência do controle de influência) e ação (capacidade de ação intencional). Segundo a teoria de John Stuart Mill (1806-1883), a pessoa em plena consciência e maturidade é soberana sobre si mesmo, seu corpo e sua mente. Seguindo essa abordagem, podemos falar em duas condições éticas: 1) as pessoas devem ser tratadas como indivíduos autônomos e 2) os indivíduos com a autonomia reduzida devem ser protegidos. Portanto duas posturas morais são esperadas: o reconhecimento da autonomia e a proteção daqueles com autonomia diminuída. Uma pessoa autônoma é aquela capaz de pensar e decidir sobre seus objetivos pessoais e de agir para alcançá-los. Respeitar a autonomia de alguém é considerar suas opiniões e escolhas e evitar obstruir suas atitudes, a não ser que elas prejudiquem outras pessoas. A capacidade de autodeterminação é desenvolvida e amadurecida durante a vida e alguns indivíduos podem perder essa capacidade total ou parcialmente devido a doenças, transtornos mentais ou situações que cerceiem a liberdade. É necessário respeitar tanto aquele sujeito que ainda não atingiu a maturidade quanto aquele que tornou-se dependente, protegendo-os a medida que amadurecem ou enquanto estiverem incapazes (Caponero e Vieira, 2006).

- Justiça: este princípio está relacionado à distribuição coerente e adequada de deveres e benefícios sociais. Podemos dizer que uma pessoa é vítima de uma injustiça quando é negado a ela um bem a que tem direito. 
A bioética trata de questões relacionadas à vida e à morte, colocando em foco discussões sobre temas como eutanásia, distanásia e o morrer com dignidade (Segre e Cohen, 1995 apud Kovács, 2003).

\subsection{Eutanásia}

A palavra Eutanásia do grego eu - bom e thanatos - morte, originalmente definia a boa morte. Eutanásia é o ato de abreviar a morte de um paciente em fase terminal. Apenas podemos falar em eutanásia se houver um pedido explícito do paciente, pois se este pedido não estiver bem definido, trata-se de homicídio, mesmo que tenha um caráter piedoso (Kovács, 2003).

Embora, em alguns casos, a eutanásia possa ser vista como um caminho para o alívio de um ser em sofrimento, sua legalização pode abrir precedentes para a diminuição de cuidados alternativos que poderiam abrandar o mesmo sofrimento, sem a necessidade de se recorrer à morte. Surge a pergunta: será que a legalização da eutanásia virá no lugar da criação de programas de cuidados paliativos? Uma grande diferença existe entre deixar morrer no momento em que a morte se faz inevitável e provocar a morte (op. cit.).

A eutanásia traz à tona dois princípios contrários: a autonomia do paciente que tem o direito de cuidar de seu próprio processo de morte e a sacralidade da vida, defendida pelas principais religiões que consideram a vida um dom de Deus e, portanto, não pode ser decidida pelo homem. No Direito Brasileiro, a Eutanásia é considerada homicídio, portanto, ilícita e imputável (op. cit.).

\subsection{Distanásia}

Distanásia, do grego dys - defeituoso e thanatos - morte, é a morte defeituosa caracterizada pela manutenção de tratamentos fúteis em pacientes sem possibilidades de recuperação, fazendo da morte um processo arrastado e sofrido, com muita agonia e ansiedade. Também conhecida como Obstinação Terapêutica e Futilidade Médica. É resultado de ações médicas que negam a 
finitude humana diante de uma doença incurável e transforma a cura em obsessão (Kovács, 2003).

O desenvolvimento tecnológico e farmacêutico permitiu que um arsenal terapêutico fosse criado e deixado à disposição dos profissionais de saúde como aparelhos de suporte à vida, novos medicamentos e transplantes de órgãos, por exemplo. Porém, o fato de um tratamento estar disponível não quer dizer que, necessariamente, ele tenha que ser utilizado e que seria útil para o paciente. Útil é um tratamento que ajuda na melhora do paciente, que o beneficia. Portanto, futilidade é a característica de alguma coisa inútil, insignificante e sem importância, que define o conceito de "obstinação terapêutica" que é o comportamento médico de utilizar terapêuticas com efeitos maléficos ou simplesmente inúteis diante da cura impossível e com efeitos benéficos menores do que os inconvenientes causados ao paciente. A distanásia seria então o prolongamento exagerado da morte de um paciente através de tratamentos inúteis. Seria uma atitude para "salvar" a vida do paciente em fase terminal da doença, submetendo-o a um sofrimento enorme (Caponero e Vieira, 2006).

\subsection{Ortotanásia}

Após a redefinição de saúde pela Organização Mundial de Saúde como o bem-estar físico, mental, social e espiritual foi possível se falar no conceito de saúde do doente em fase terminal e criar o conceito de Ortotanásia (Pessini, 2006).

A ortotanásia é a possibilidade de supressão de meios artificiais para manter a vida quando o organismo não é mais capaz de mantê-la sozinho, ou seja, a possibilidade de se desligar os aparelhos ou suspender medicamentos, quando o tratamento é considerado fútil, não promove mais a recuperação e causa mais sofrimento ao paciente. Não é considerada ilícita. A conduta de desligar os aparelhos ou suspender tratamentos será legal se não significar o abreviamento da vida e obedecer ao princípio da não maleficência (Kovács, 2003).

A ortotanásia visa respeitar a dignidade no viver e morrer do paciente, assim como seu bem-estar total. A ética nesse processo é tão importante quanto 
à técnica. O desafio é reunir a sensibilidade ética e humana ao conhecimento científico e técnico numa abordagem multidisciplinar. Os princípios éticos dos cuidados paliativos são:

1) Cuidado integral, levando em conta bem-estar físico, emocional, social e espiritual do paciente;

2) Apoio à família, que é o núcleo principal de apoio do paciente;

3) Incentivo à autonomia e dignidade do paciente, onde ele possa participar da construção dos objetivos terapêuticos;

4) Conceito de terapia ativa, não sendo aceitável a postura de "não há mais nada a fazer", pois o cuidado pode continuar quando o curar não é mais possível;

5) Ambiente favorável, sendo necessário criar-se um ambiente de respeito, apoio e comunicação em torno do paciente;

6) Trabalho multidisciplinar (Pessini, 2006)

Os programas de cuidados paliativos poderiam ser uma solução entre a eutanásia e a distanásia, a operacionalização da ortotanásia, a morte na hora certa. Pacientes em fase final de vida que são cuidados através dos cuidados paliativos têm, sempre que possível, sua dor e sintomas aliviados e a qualidade de suas vidas é foco da equipe de saúde que o assiste. Portanto, os cuidados paliativos trazem um avanço significativo e promissor no que diz respeito aos cuidados de fim de vida, devolvendo ao paciente sua dignidade e bem estar, dando-Ihe a oportunidade de viver e conduzir sua própria morte, respeitando sua autonomia e não o abandonando (Kovács, 2003).

Em dezembro de 2010, a justiça brasileira validou a Resolução 1.805/2006 que trata de critérios para a prática da ortotanásia. Com a decisão, o médico autorizado pelo paciente ou seu responsável legal pode limitar ou suspender tratamentos exagerados e desnecessários que prolonguem a vida do doente em fase terminal de enfermidades graves e incuráveis. Essa possibilidade está prevista desde que exista autorização expressa do paciente ou de seu responsável legal. A decisão entende que a ortotanásia se insere no contexto científico da Medicina Paliativa. Diz o documento:

"Diagnosticada a terminalidade da vida, qualquer terapia extra se afigurará ineficaz. Assim, já não se pode aceitar que o médico deva fazer tudo para salvar a vida do paciente (beneficência), se esta vida 
não pode ser salva. Desse modo, sendo o quadro irreversível, é melhor caso assim o paciente e sua família o desejem - não lançar mão de cuidados terapêuticos excessivos e ineficazes, que apenas terão 0 condão de causar agressão ao paciente. Daí é que se pode concluir que, nessa fase, o princípio da não-maleficência assume uma posição privilegiada em relação ao princípio da beneficência - visto que nenhuma medida terapêutica poderá realmente fazer bem ao paciente".

A Resolução n 1.865/2010 representa uma nova ética nas ciências da saúde, que surge na tentativa de derrubar antigos tabus e enfrentar problemas da área da saúde de forma mais realista, trazendo a dignidade humana para o foco das discussões (CFM, 2011).

A ética em saúde é caracterizada pelo bem pensar e pelo auto-exame diante das práticas, não sendo suficiente apenas boa intenção. A auto-avaliação nos permite descobrir que não somos onipotentes, que falhamos, e, por vezes, somos frágeis e insuficientes, necessitando de mútua compreensão (Koerich, Machado e Costa, 2005).

Diante desse cenário, a bioética é um instrumento que guiará as reflexões diárias de nosso trabalho na tentativa de desempenhar nossa função com a maior qualidade possível sempre com o foco no bem estar do paciente. Os profissionais de saúde precisam estar familiarizados com a bioética e integrar os conceitos e teorias éticas às responsabilidades clínicas. A bioética clínica é por sua vez uma prática interpessoal e intrapessoal envolvendo aspectos do relacionamento do médico com seu paciente (Marcolino e Cohen, 2008). 


\section{Conclusão}

No início do século $X X$, os profissionais de saúde sentiam-se orgulhosos dos avanços da tecnologia e da medicina, com uma idéia arrogante de que poderiam controlar a morte. Atualmente, curvam-se diante dessa impossibilidade, mas talvez possam estar orgulhosos por poderem ter a proximidade da morte como conselheira em seu trabalho admirável de cuidar de pacientes em fase terminal de doença (Kóvacs,1999).

Nesse contexto, os Cuidados Paliativos surgem como alternativa de modelo de gestão de fim de vida para aqueles pacientes que se aproximam da morte, que não necessariamente precisa ser acompanhada de um sofrimento desumano, de isolamento e tabus.

O paciente em fase terminal de doença pode e precisa receber cuidados que priorizem a qualidade de vida e seu bem-estar físico, psicológico, social e espiritual. Precisa ser ouvido e, principalmente, ser respeitado em todos os seus desejos e opções, pois como ser autônomo tem o direito de escolher que tipo de tratamento quer receber e que rumo terá seu processo de morte. É necessário que ele seja acompanhado de perto por uma equipe multiprofissional e tenha todas as suas dores aliviadas.

A dor, como vimos, é um dos sintomas mais destrutivos em doenças terminais e pode ser aumentada ou diminuída pela dimensão psicológica. $\mathrm{O}$ medo, a ansiedade, a depressão, os sentimentos de vulnerabilidade, abandono, impotência, solidão, assim como a experiência de se deparar com a própria finitude são aspectos emocionais que, freqüentemente, estão presentes nesses pacientes, fazendo com que o processo de fim de vida seja vivenciado de forma ainda mais assustadora. Por isso, se faz necessário a presença de profissionais da saúde mental nas equipes paliativistas para acompanhar esses pacientes nessa jornada, auxiliando e abrandando essas angústias na medida do possível.

Como podemos observar, quando uma pessoa adoece, sua família adoece junto com ela. Vivencia uma gama de sentimentos parecida com a do paciente, tem sua rotina modificada e sua estrutura abalada. Seus membros podem adoecer tanto física quanto psicologicamente, pois deparar-se com a 
degeneração de um ente querido traz emoções intensas e perturbação emocional. Cada membro da família irá reagir de uma forma ao processo de adoecimento e morte, portanto além dos cuidados dispensados a essas pessoas, é preciso respeitar como cada uma sentirá sua perda. Assim como o paciente, a família precisa ser ouvida pela equipe médica para que possa estabelecer um vínculo de confiança, tendo a certeza de que os melhores cuidados estão sendo ministrados ao paciente. $O$ atendimento das necessidades da família sejam elas práticas, psicológicas, sociais ou espirituais, indiretamente, beneficia o paciente.

Durante o desenvolvimento do trabalho, constata-se a importância da saúde física e psicológica da equipe de saúde. A difícil e desgastante rotina de lidar com morte expõe esses profissionais a níveis elevados de estresse, além de facilitar o surgimento de comorbidades psicológicas. Sentir, ouvir, olhar e tocar o sofrimento alheio diariamente é uma tarefa que pode levar a equipe a uma sobrecarga extrema e ao desenvolvimento de mecanismos de defesa, acarretando uma assistência de má qualidade. O apoio psicológico a essa equipe é fundamental. Ela precisa ter espaço para trabalhar sua subjetividade, para ser ouvida, para falar, para trocar experiências, para reconstruir emoções e elaborar perdas, desenvolvendo condições psicológicas adequadas para estar nessa função.

Os princípios bioéticos que permeiam a filosofia dos Cuidados Paliativos são a base necessária para guiar a prática. É com apoio nos pilares da beneficência, não-maleficência, autonomia e justiça que as decisões nos cuidados de fim de vida devem ser tomadas, evitando o abreviamento da morte e o prolongamento da vida através de angústia e sofrimento, priorizando uma abordagem de respeito à dignidade do paciente, deixando-o morrer no momento em que a morte se faz inevitável, porém cercado de todos os cuidados possíveis para que não haja sofrimento e dor.

Podemos concluir que o paciente, a família e equipe de saúde vivenciam situações e sentimentos que abalam e desorganizam seu psiquismo ao se depararem com a inevitabilidade da morte. Cuidar do psicológico desses sujeitos é tão necessário quanto cuidar do aspecto físico, do social e espiritual, pois são formados por todos eles e precisam ser compreendidos em todas as suas dimensões. Dessa forma, a presença do psicólogo dentro da equipe 
multiprofissional se faz fundamental, para auxiliar na elaboração dos sentimentos e questões suscitadas pelo processo do morrer.

Falar sobre cuidados paliativos não é uma tarefa fácil, pois questões relacionadas ao fim de vida não são muito discutidas em nossa sociedade ainda hoje. É preciso modificar a idéia de que nada pode ser feito por esses pacientes. Muito pode se fazer para o bem-estar daqueles que estão sofrendo ou se aproximando dos momentos finais de vida, e que esses momentos não precisam ser vivenciados nem com abandono nem com tratamentos dolorosos e fúteis. 


\section{Referências Bibliográficas}

- Caponero R, Vieira DE. "Urgências em cuidados paliativos". In: Pimenta CAM, Mota DDCF, Cruz DALM (Org). Dor e cuidados paliativos: Enfermagem, Medicina e Psicologia. São Paulo: Manole, 2006.

- Carvalho MVB, Merighi MAB. "O cuidar no processo de morrer com dignidade". In: Pimenta CAM, Mota DDCF, Cruz DALM (Org). Dor e cuidados paliativos: Enfermagem, Medicina e Psicologia. São Paulo: Manole, 2006.

- Carvalho VA. "A equipe de saúde e suas vicissitudes emocionais". In: Pimenta CAM, Mota DDCF, Cruz DALM (Org). Dor e cuidados paliativos: Enfermagem, Medicina e Psicologia. São Paulo: Manole, 2006.

- Colatusso ECF, Santos RLP, Andrade GAL, Dyniewicz AM. "Enfermeiras em um ambulatório de dor e cuidados paliativos: Retrospectiva histórica, ações e questões atuais". In: Pimenta CAM, Mota DDCF, Cruz DALM (Org). Dor e cuidados paliativos: Enfermagem, Medicina e Psicologia. São Paulo: Manole, 2006.

- Conselho Federal de Medicina. "Resolução 1.865/2010". Disponível em: http://portal.cfm.org.br. Acesso em 12 abr 2011.

- Floriani CA, Schramm FR. "Casas para os que morrem: a história do desenvolvimento dos hospices modernos". Hist. cienc. saudeManguinhos, Rio de Janeiro, 2011 . Disponível em $<$ http://www.scielo.br/scielo.php?script=sci_arttext\&pid=S010459702010000500010\&lng=pt\&nrm=iso >. acessos em 10 jan. 2011. doi: $10.1590 / S 0104-5970201000050001$

- Fortes PAC. "Reflexões sobre a bioética e o consentimento esclarecido". 1994. Disponível em :

http://revistabioetica.cfm.org.br/index.php/revista bioetica/article/viewArtic le/458 Acesso: 02 abr 2011 
- Koerich MS, Machado RR, Costa E. "Ética e bioética: para dar início à reflexão". Texto contexto - enferm., Florianópolis, v. 14, n. 1, mar.

2005. Disponível em

http://www.scielo.br/scielo.php?script=sci_arttext\&pid=S0104-

07072005000100014\&lng=pt\&nrm=iso. Acessos em 12 abr. 2011. doi: 10.1590/S0104-07072005000100014.

- Kovács MJ. Morte e Desenvolvimento Humano. São Paulo: Casa do Psicólogo, 1992.

- Kóvacs MJ. "Pacientes em estágio avançado da doença, a dor da perda e da morte”. In: Carvalho MMMJ (Org). Dor: um estudo multidisciplinar. São Paulo: Summus, 1999.

- Kovács, MJ. "Bioética nas questões da vida e da morte". Psicol. USP, São Paulo, v. 14, n. 2, 2003 . Disponível em $<$ http://www.scielo.br/scielo.php?script=sci_arttext\&pid=S010365642003000200008\&lng=pt\&nrm=iso $>$. acessos em 19 fev. 2011. doi: $10.1590 /$ S0103-65642003000200008.

- Kovács MJ. Educação para a morte: temas e reflexões. São Paulo: Casa do Psicólogo: FAPESP, 2003.

- Kovács MJ. "Comunicação em cuidados paliativos". In: Pimenta CAM, Mota DDCF, Cruz DALM (Org). Dor e cuidados paliativos: Enfermagem, Medicina e Psicologia. São Paulo: Manole, 2006.

- Kübler-Ross E. Sobre a Morte e o Morrer. São Paulo: Martins Fontes, 1996.

- Marcolino, JAM, Cohen C. "Sobre a correlação entre a bioética e a psicologia médica". Rev. Assoc. Med. Bras., São Paulo, v. 54, n. 4, ago. 2008 . Disponível em $<$ http://www.scielo.br/scielo.php?script=sci_arttext\&pid=S010442302008000400024\&lng=pt\&nrm=iso $>$. acessos em 13 abr. 2011. doi: 10.1590/S0104-42302008000400024. 
- Marinho S, Aran M. "As práticas de cuidado e a normalização das condutas: algumas considerações sobre a gestão sociomédica da "boa morte" em cuidados paliativos". Interface (Botucatu), Botucatu, v. 15, n. 36, mar. 2011. Disponível em $<$ http://www.scielo.br/scielo.php?script=sci_arttext\&pid=S1414$32832011000100002 \& \mathrm{lng}=\mathrm{pt} \& \mathrm{nrm}=\mathrm{iso}>$. acessos em $01 \mathrm{mar}$. 2011. Epub 10-Dez-2010. doi: 10.1590/S1414-32832010005000039.

- Melo AGC, Figueiredo MTA. "Cuidados paliativos: Conceitos básicos, histórico e realizações da Associação Brasileira de Cuidados paliativos e da Associação Internacional de Hospice e Cuidados Paliativos". In: Pimenta CAM, Mota DDCF, Cruz DALM (Org). Dor e cuidados paliativos: Enfermagem, Medicina e Psicologia. São Paulo: Manole, 2006.

- Menezes RA. "Tecnologia e "Morte Natural": o morrer na contemporaneidade". Physis, Rio de Janeiro, v. 13, n. 2, dez. 2003. Disponível em <http://www.scielo.br/scielo.php?script=sci_arttext\&pid=S010373312003000200008\&lng=pt\&nrm=iso $>$. acessos em 15 jan. 2011. doi: $10.1590 / S 0103-73312003000200008$

- Menezes RA. Em busca da boa morte: antropologia da boa morte. Rio de Janeiro. Garamond: Fiocruz, 2004.

- Muccillo N. "O preparo do corpo após a morte: aspectos culturais, cuidados físicos e emocionais". In: Pimenta CAM, Mota DDCF, Cruz DALM (Org). Dor e cuidados paliativos: Enfermagem, Medicina e Psicologia. São Paulo: Manole, 2006.

- Oliveira EA, Santos MA, Mastropietro AP. "Apoio psicológico na terminalidade: ensinamentos para a vida”. Psicol. estud., Maringá, v. 15, n. 2, jun. 2010 . Disponível em $<$ http://www.scielo.br/scielo.php?script=sci_arttext\&pid=S1413$73722010000200002 \& \operatorname{lng}=p t \& n r m=i s o>$. acessos em 18 fev. 2011. doi: 10.1590/S1413-73722010000200002. 
- Oliveira AC, Silva MJP. "Autonomia em cuidados paliativos: conceitos e percepções de uma equipe de saúde". Acta paul. enferm., São Paulo, v. 23, n. 2, abr. 2010 . Disponível em <http://www.scielo.br/scielo.php?script=sci_arttext\&pid=S010321002010000200010\&lng=pt\&nrm=iso $>$. acessos em 10 abr. 2011. doi: 10.1590/S0103-21002010000200010.

- Prade CF, Casellato G, Silva ALM. "Cuidados paliativos e comportamento perante a morte". In: Knobel E, Andreoli PBA, Erlichman MR. Psicologia e Humanização: assistência aos pacientes graves. São Paulo. Atheneu: 2008.

- Pessini L. Como lidar com o paciente em fase terminal. 5a ed. São Paulo: Edições Loyola; 2003.

- Pessini L. "Bioética e cuidados Paliativos: alguns desafios do cotidiano aos grandes dilemas". In: Pimenta CAM, Mota DDCF, Cruz DALM (Org). Dor e cuidados paliativos: Enfermagem, Medicina e Psicologia. São Paulo: Manole, 2006.

- Silva ARB, Gonçalves SP. "Cuidando de mulheres com câncer ginecológico e mamário: A vivência de enfermeiras em cuidados paliativos". In: Pimenta CAM, Mota DDCF, Cruz DALM (Org). Dor e cuidados paliativos: Enfermagem, Medicina e Psicologia. São Paulo: Manole, 2006.

- Silva RCF, Hortale VA. "Cuidados paliativos oncológicos: elementos para o debate de diretrizes nesta área”. Cad. Saúde Pública, Rio de Janeiro, v. 22, n. 10, out. 2006 . Disponível em <http://www.scielo.br/scielo.php?script=sci_arttext\&pid=S0102311X2006001000011\&lng=pt\&nrm=iso >. acessos em 20 fev. 2011. doi: 10.1590/S0102-311X2006001000011.

- Soares M, Terzi RGG, Piva JP. "Série temática: terminalidade da vida e cuidados de final de vida na unidade de terapia intensiva". Rev. bras. ter. 
intensiva, São Paulo, v. 19, n. 3, set. 2007 . Disponível em

<http://www.scielo.br/scielo.php?script=sci_arttext\&pid=S0103-

507X2007000300016\&lng=pt\&nrm=iso > . acessos em 17 mar. 2011.

doi: 10.1590/S0103-507X2007000300016.

- Teixeira M, Lavor M. "Assistência no modelo hospice: a experiência do INCA". In: Pimenta CAM, Mota DDCF, Cruz DALM (Org). Dor e cuidados paliativos: Enfermagem, Medicina e Psicologia. São Paulo: Manole, 2006.

- WORLD HEALTH ORGANIZATION - WHO. "Definition of palliative care". 2002. Disponível em: http://www.who.int/cancer/palliative/definition/en/. Acesso em 21 fev. 2011. 